\title{
The reference interval of blood pressure is essential for preemptive medicine in the prediction and prevention of hypertension
}

\author{
Minoru Yamakado1,2* MD, PhD \\ ${ }^{1}$ Faculty of Nursing, Ashikaga University, Japan \\ ${ }^{2}$ Nihonbashi-Muromaci Mitsui Tower, Midtown Clinic, Japan
}

The Ningen Dock Medical Checkup is a unique medical checkup system conducted electronically in a Ningen Dock facility for the early detection and prevention of cancer and lifestyle-related diseases such as obesity, hypertension, lipid disorders and glucose metabolism disorders by risk management [1]. The detection of early stage lifestylerelated diseases requires a number of relevant clinical tests, and further requires a frame of reference to access these test results. Although this frame of reference consists of the reference intervals (RIs), these RIs are often set for each medical checkup facility, even if the test results at different facilities are similar. Therefore, in order to provide highquality medical examinations uniformly throughout the country, it is necessary to set standardized RIs that could be adopted by all Ningen Dock facilities nationwide. Based on this way of thinking, we have now established new RIs for basic laboratory tests [2]. Especially in Japan where cerebrovascular disease is a prevalent cause of death and reduces healthy life expectancy, we also described the RIs for blood pressure (BP) that indicate cerebrovascular disease, and their use in preventive medicine. In addition, in the treatment of hypertension, the Japanese Society of Hypertension Guidelines for the Management of Hypertension (JSH 2019 Guidelines) show the classification of blood pressure and the procedure for treatment of hypertension [3]. These clinical decison limits (CDLs) and the RIs used for interpretation of the results of medical examinations are two different concepts and so should be used separately.

A total of 188 Ningen Dock institutions cooperated in this study. A total of 1,499,288 subject records ( 907,079 men with age range of 33 to 73 years and median age of 50 years; and 592,209 women with age range of 31 to 72 years and median age of 49 years) were obtained and merged for derivation of RIs. For derivation of RIs, we first defined healthy individuals as those with a body mass index (BMI) $<25 \mathrm{~kg} / \mathrm{m}^{2}$, no habit of cigarette smoking, an average daily alcohol consumption not exceeding 1 glass of sake (approximately $22 \mathrm{~g}$ ethanol/day), systolic $\mathrm{BP}(\mathrm{SBP})<130 \mathrm{mmHg}$ and diastolic blood $\mathrm{BP}$ (DBP) $<85 \mathrm{mmHg}$, and neither receiving any medication for chronic diseases nor having any history of life threatening diseases such as malignancy, cardiovascular events, or stroke. All records were anonymized by decoding ID information. Approval for this study was obtained from the Ethical Committee of Japanese Society of Ningen Dock (JSND) after critical evaluation of ethical/scientific requirements (JSND-EC: 2012-001).

RIs were derived by parametric method based on Gaussian transformation of reference values using modified Box-Cox transformation formula [4]. Original software developed for the

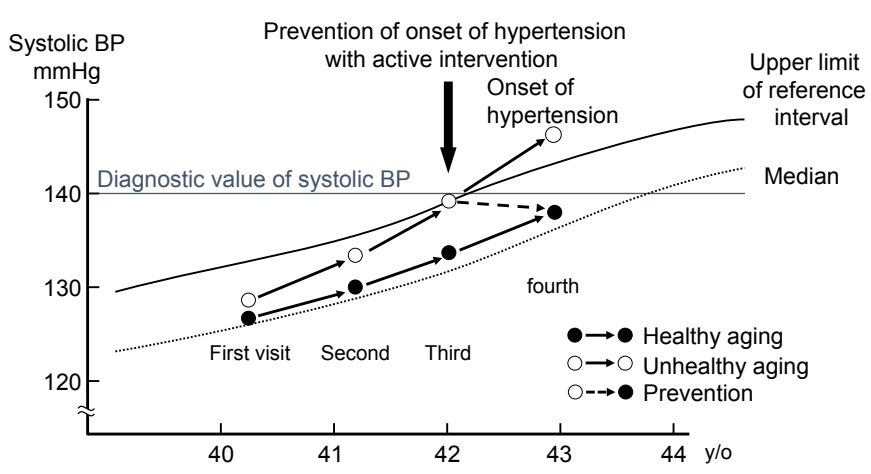

Figure 1. New usage of gender- and age-specific reference intervals of systolic blood pressure (SBP) for preemptive medicine in preventive medicine.

derivation of RIs with a built-in capability of flexible application of the LEVE method was employed for the derivation [5]. The $90 \%$ confidence interval for limits of RIs was estimated by the bootstrap method through 20-time repeated resampling of records chosen for not having any abnormal results for the reference tests. The need for partitioning reference values by gender- and age-group was judged by SD ratio (SDR) introduced by Ichihara [6].

Table 1 shows changes in SBP and DBP of men and women by age group every 5 years. The upper limit of SBP was $146 \mathrm{mmHg}$ and the upper limit of DBP was $94 \mathrm{mmHg}$ in both gender, the upper limit of SBP was $148 \mathrm{mmHg}$ and the upper limit of DBP was $96 \mathrm{mmHg}$ in men, and the upper limit of SBP was $141 \mathrm{mmHg}$ and the upper limit of DBP was $89 \mathrm{mmHg}$ in women. These results are apparently exceeded from CDLs for therapeutic intervention of the JSH 2019 Guidelines for SBP of $140 \mathrm{mmHg}$ and DBP of $90 \mathrm{mmHg}$.

As mentioned above, in the treatment of hypertension we should follow the JSH 2019 Guidelines. We believe that the clinical applications of these new RIs should improve preemptive medicine in the prediction and prevention of diseases in future medical examinations. The concept is shown in Figure 1. By potting the SBP of the examinee within the RIs according to age and tracking it over time, the occurrence of

${ }^{\star}$ Correspondence to: Minoru Yamakado, Faculty of Nursing, Ashikaga University, 3-2100-1 Honjyo, Ashikaga City, Tochigi, 326-0808, Japan, Tel: +81 284 21 8242; Fax: +81 28421 1270; E-mail: yamakado.minoru@v90.ashitech.ac.jp

Received: April 15, 2020; Accepted: April 27, 2020; Published: April 30, 2020 
Yamakado M (2020) The reference interval of blood pressure is essential for preemptive medicine in the prediction and prevention of hypertension

Table 1. Gender and age-specific reference intervals for systolic blood pressure (SBP) and diastolic blood pressure (DBP) of men and women by age group every 5 years.

\begin{tabular}{|c|c|c|c|c|c|c|c|c|c|c|c|}
\hline \multicolumn{6}{|c|}{ Men and women } & \multirow[b]{2}{*}{ Lower } & \multirow{2}{*}{$\begin{array}{c}\text { Men } \\
\text { Median }\end{array}$} & \multirow[b]{2}{*}{ Upper } & \multirow[b]{2}{*}{ Lower } & \multirow{2}{*}{$\begin{array}{l}\text { Women } \\
\text { Median }\end{array}$} & \multirow[b]{2}{*}{ Upper } \\
\hline Item & Unit & Age & Lower & Median & Upper & & & & & & \\
\hline \multirow{10}{*}{ SBP } & \multirow{10}{*}{$\mathrm{mmHg}$} & $30-34$ & 86 & 106 & 133 & 91 & 111 & 136 & 85 & 102 & 126 \\
\hline & & $35-39$ & 87 & 107 & 135 & 92 & 112 & 138 & 86 & 103 & 129 \\
\hline & & $40-44$ & 87 & 109 & 139 & 93 & 113 & 143 & 87 & 105 & 135 \\
\hline & & $45-49$ & 88 & 111 & 144 & 92 & 115 & 146 & 87 & 107 & 140 \\
\hline & & $50-54$ & 90 & 113 & 150 & 93 & 117 & 151 & 88 & 110 & 147 \\
\hline & & $55-59$ & 89 & 116 & 151 & 94 & 119 & 153 & 86 & 112 & 147 \\
\hline & & $60-64$ & 90 & 119 & 155 & 94 & 121 & 157 & 88 & 115 & 152 \\
\hline & & $65-69$ & 91 & 121 & 157 & 93 & 122 & 157 & 90 & 119 & 156 \\
\hline & & $70-74$ & 92 & 122 & 160 & 92 & 123 & 159 & 91 & 121 & 161 \\
\hline & & $75-79$ & 91 & 125 & 160 & 91 & 125 & 160 & 94 & 124 & 161 \\
\hline \multirow{10}{*}{ DBP } & \multirow{10}{*}{$\mathrm{mmHg}$} & $30-34$ & 49 & 65 & 84 & 51 & 68 & 86 & 48 & 62 & 81 \\
\hline & & $35-39$ & 51 & 66 & 87 & 54 & 70 & 89 & 49 & 64 & 83 \\
\hline & & $40-44$ & 51 & 68 & 91 & 55 & 71 & 94 & 50 & 65 & 87 \\
\hline & & $45-49$ & 51 & 70 & 94 & 56 & 73 & 97 & 50 & 67 & 90 \\
\hline & & $50-54$ & 53 & 71 & 98 & 56 & 75 & 99 & 51 & 68 & 93 \\
\hline & & $55-59$ & 53 & 73 & 96 & 56 & 76 & 98 & 52 & 70 & 93 \\
\hline & & $60-64$ & 54 & 74 & 97 & 57 & 76 & 99 & 52 & 70 & 95 \\
\hline & & $65-69$ & 54 & 74 & 96 & 56 & 76 & 97 & 53 & 71 & 95 \\
\hline & & $70-74$ & 53 & 74 & 95 & 55 & 74 & 96 & 51 & 71 & 93 \\
\hline & & $75-79$ & 53 & 73 & 93 & 53 & 74 & 94 & 54 & 71 & 95 \\
\hline
\end{tabular}

hypertension can be predicted and active intervention at that time can prevent the occurrence of hypertension. For this purpose, gender- and age-specific RIs are required.

\section{References}

1. Yamakado M (2010) Taking stock of the Ningen Dock. Highlighting Japan 10: 1-5.

2. Yamakado M, Ichihara K, Matsumoto Y (2015) Derivation of gender and age-specific reference intervals from fully normal Japanese individuals and the implications for health screening. Clin Chim Acta; 447: 105-114. [Crossref]
3. Umemura S, Arima H, Arima S (2019) The Japanese Society of Hypertension Guidelines for Management of Hypertension (JSH 201). Hypertens Res 42: 1235-1481. [Crossref]

4. Ichihara K, Boyd J (2010) An appraisal of statistical procedures used in derivation of reference intervals. Clin Chem Lab Med 48: 1537-1551. [Crossref]

5. Ichihara K (2014) Statistical considerations for harmonization of the global multicenter study on reference values. Clin Chim Acta 432: 108-118. [Crossref]

6. Ichihara K, Itoh Y, Lam CWK (2008) Sources of variation of commonly measured serum analysis among 6 Asian cities and consideration of common reference intervals. Clin Chem 54: 356-365. [Crossref]

Copyright: (C2020 Yamakado M. This is an open-access article distributed under the terms of the Creative Commons Attribution License, which permits unrestricted use, distribution, and reproduction in any medium, provided the original author and source are credited. 